\title{
Immunohistochemical analyses to determine pathogenesis of tenosynovitis with psammomatous calcification in the wrist: A case report
}

\author{
CHIKA MIYASAKA ${ }^{1}$, MITSUAKI ISHIDA ${ }^{1}$, YOSHITAKA HAMADA ${ }^{2}$, TAKEYASU TOYAMA ${ }^{2}$ and KOJI TSUTA ${ }^{1}$ \\ Departments of ${ }^{1}$ Pathology and Laboratory Medicine, and ${ }^{2}$ Orthopedic Surgery, \\ Kansai Medical University, Hirakata, Osaka 573-1010, Japan
}

Received December 27, 2018; Accepted May 22, 2019

DOI: $10.3892 /$ br.2019.1218

\begin{abstract}
Tenosynovitis with psammomatous calcification is an extremely rare clinicopathological condition, which is characterized histopathologically by the presence of numerous psammomatous calcifications surrounded by a granulomatous reaction comprising a mixture of histiocytes and fibroblasts. The pathogenesis of this disease remains unclear, although an association with repetitive tendinous injury has been proposed. The present study describes the details of a case in an elderly Japanese female, and, to the best of our knowledge, the first known immunohistochemical analysis of the mechanism underlying psammomatous calcification formation. A 66-year-old Japanese woman presented with pain in the right wrist. The lesion was surgically resected. Histopathological examination revealed a well-circumscribed lesion composed of psammomatous calcification. The calcification was surrounded by histiocytes, and a few multinucleated giant cells and fibroblastic spindle cells. Immunohistochemical study revealed that these histiocytes were positive for cluster of differentiation 163, and the histiocytes and spindle cells surrounding the psammomatous calcification expressed bone morphogenetic protein-1 (BMP-1). Tenosynovitis with psammomatous calcification is hypothesized to be a distinctive subtype of idiopathic calcifying tenosynovitis involving an unusual reactive or degenerative process. BMP-1 has been demonstrated to be involved in the regulation of hard tissue mineralization, and its expression has been suggested to be associated with psammoma formation in papillary thyroid cancer. To the best of our knowledge, the case report within the present study suggested for the first time
\end{abstract}

Correspondence to: $\mathrm{Dr}$ Mitsuaki Ishida, Department of Pathology and Laboratory Medicine, Kansai Medical University, 2-5-1 Shinmachi, Hirakata, Osaka 573-1010, Japan

E-mail: ishidamt@hirakata.kmu.ac.jp

Key words: tenosynovitis with psammomatous calcification, psammoma, bone morphogenetic protein-1 that BMP-1 expression was associated with development of psammomatous calcification in this condition.

\section{Introduction}

Tenosynovitis with psammomatous calcification is an extremely rare clinicopathological condition. Since it was first described by Gravanis and Gaffney in 1983 (1), only a few additional cases have been examined in the English language literature (2-5). This variant of calcifying tenosynovitis or calcific tendonitis is characterized histopathologically by the presence of numerous psammomatous calcifications surrounded by a granulomatous reaction comprising a mixture of histiocytes and fibroblasts (2-5). Recently, Michal et al (6) investigated a large case series of this disease, and confirmed that the disease exhibited a tendency to affect the fingers or toes of young to middle-aged women, and appeared to be associated with trauma and/or repetitive activity. They concluded that tenosynovitis with psammomatous calcification is a distinctive trauma-associated subtype of idiopathic calcifying tenosynovitis.

However, the pathogenesis of tenosynovitis with psammomatous calcification remains unclear. Although an association of this disease with repetitive tendinous injury has been described previously $(2,6)$, other studies have described cases without a history of trauma $(3,4)$. Bone morphogenetic protein (BMP)-1, also known as procollagen C-peptidase, is a multifunctional protein regulating of hard tissue mineralization (7). BMP-1 expression has been suggested to be associated with ectopic ossification (8) and psammoma formation in papillary thyroid cancer (9). The present study described a case report of tenosynovitis with psammomatous calcification that occurred in the wrist of an elderly female, and the immunohistochemical analysis of the mechanism of psammomatous calcification formation, particularly association with BMP-1 expression.

\section{Case report}

A 66-year-old Japanese female presented with pain in the right wrist. She had a history of De Quervain's disease and infliximab use for ulcerative colitis, but no history of trauma to the 
wrist. Radiographic imaging demonstrated a calcified lesion in the palmar side of the right wrist, around the lunar and capitate bones. The lesion was surgically resected following a clinical diagnosis of ectopic bone formation.

Samples were fixed in $10 \%$ formalin at room temperature for $24 \mathrm{~h}$ and paraffin-embedded specimens $\left(60^{\circ} \mathrm{C}\right.$, $4 \mathrm{~h}$ ) of the resected lesion were processed for routine histological examination and immunohistochemical analyses. Immunohistochemical analyses were performed using autostainers (XT System Benchmark; OptiView DAB Universal Kit, Roche Diagnostics) and Autostainer link 48 (Envision FLEX; cat. no. K8000; Dako; Agilent Technologies). The primary antibodies used were a mouse monoclonal antibody against $\alpha$-smooth muscle actin ( $\alpha$-SMA; clone name, 1A4; $20 \mathrm{~min}$ at room temperature; Dako; Agilent Technologies), a rabbit polyclonal antibody against BMP-1 (cat. no. ab205394; $32 \mathrm{~min}$ at room temperature; Abcam) and a mouse monoclonal antibody against CD163 (clone name, 10D6; $32 \mathrm{~min}$ at room temperature; Leica Microsystems, Ltd). Light microscopic examination of $3-\mu \mathrm{m} \mathrm{H} \& \mathrm{E}$-stained (hematoxylin, $3 \mathrm{~min}$ and eosin, $5 \mathrm{~min}$ at room temperature) sections (magnification, $\mathrm{x} 12.5, \mathrm{x} 100$ and $\mathrm{x} 400)$ revealed a well-circumscribed lesion with a central cystic cavitation (Fig. 1A), and the notable feature of numerous psammomatous calcifications (Fig. 1B). These calcifications were surrounded by histiocytes, and a few multinucleated giant cells and fibroblastic spindle cells (Fig. 1C). Neither foamy cells nor siderophages were observed within the lesion.

Light microscopic analyses of immunohistochemistry (magnification, $\mathrm{x} 400$ ) revealed that these histiocytes were positive for CD163 (Fig. 1D). A small number of $\alpha$-SMA-positive spindle cells were also detected, and the histiocytes and spindle cells surrounding the psammomatous calcification expressed BMP-1 (Fig. 1E). Based on these features, a final diagnosis of tenosynovitis with psammomatous calcification was made.

\section{Discussion}

In the present report, a case of tenosynovitis with psammomatous calcification was described. In addition, to the best of our knowledge, this was the first time immunohistochemical analysis was used to identify the potential mechanism of psammoma formation. Table I summarizes the clinicopathological features of the case in the present study, and those of previously described cases. As demonstrated, this disease affects patients with a median age of 44 years (14-83 years), with a female predominance (male:female ratio, 4:30), particularly in young to middle-aged women. Of the patients examined previously and in the presents study, 12 of 25 had a history of trauma or repetitive activity. The majority of cases occurred in the hand, in particular in the finger, or the foot, and the most common complaint was a painful mass. A previous study involving the largest case series revealed these aforementioned clinicopathological features of tenosynovitis with psammomatous calcification (6), which is believed to be a distinct clinicopathological condition involving an unusual reactive or degenerative process in the chronically traumatized tendon and peritendinous tissue $(2,6)$. However, the underlying molecular mechanism of development of this disease remains unclear.
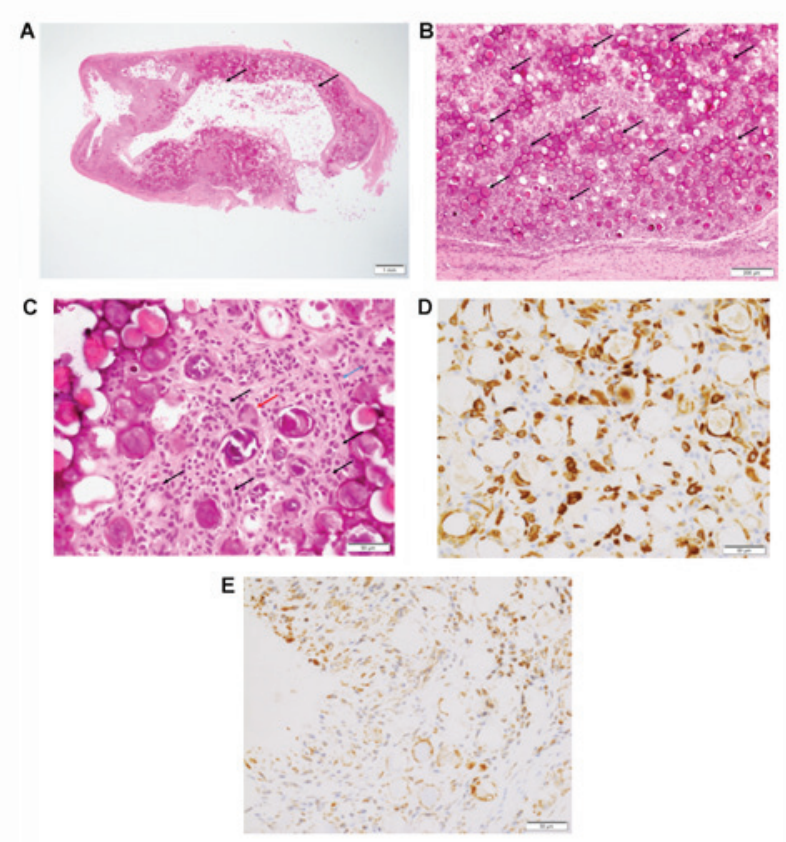

Figure 1. Histopathological and immunohistochemical features of the surgically resected wrist lesion. (A) A well-circumscribed lesion with central cystic cavitation (indicated by arrows), visualized using $H \& E$ staining (magnification, x12.5; scale bar, $1 \mathrm{~mm}$ ). (B) Numerous psammomatous calcifications are observed (indicated by arrows), visualized using $\mathrm{H} \& \mathrm{E}$ staining (magnification, x100; scale bar, $200 \mu \mathrm{m}$ ). (C) Histiocytes (indicated by black arrows) and spindle cells (indicated by the blue arrow) are present around the calcification. A multinucleated giant cell is also visible (indicated by the red arrow), visualized using H\&E staining (magnification, x400; scale bar, $50 \mu \mathrm{m}$ ). (D) Cluster of differentiation 163-positive histiocytes are present around the calcification (magnification, $\mathrm{x} 400$; scale bar, $50 \mu \mathrm{m}$ ). (E) Bone morphogenetic protein-1 expression is noted in the histiocytes and spindle cells around the calcification (magnification, $\mathrm{x} 400$; scale bar, $50 \mu \mathrm{m}$ ).

BMP-1, also known as procollagen C-peptidase may convert a variety of precursor proteins, including procollagen and dentin matrix protein, into active forms, resulting in their involvement in cell adhesion and the regulation of hard tissue mineralization (7). Therefore, the present study focused on the association between psammomatous calcification of this lesion and BMP-1 expression. From the data in the present study, the expression of BMP-1 in histiocytes and spindle cells surrounding the psammomatous calcification was clearly observed. This suggests that the expression of BMP-1 may be associated with the development of psammomatous calcification.

In conclusion, the present study described a typical case of tenosynovitis with psammomatous calcification and reviewed its clinicopathological characteristics. The results suggested that the expression of BMP-1 in the histiocytes and spindle cells surrounding the psammomatous calcification may be associated with development of this condition.

\section{Acknowledgements}

Not applicable.

\section{Funding}

No funding was received. 
Table I. Clinicopathological features of tenosynovitis with psammomatous calcification.

\begin{tabular}{|c|c|c|c|c|c|c|c|}
\hline Author, year & $\begin{array}{c}\text { Case } \\
\text { no. }\end{array}$ & $\begin{array}{l}\text { Age, } \\
\text { years }\end{array}$ & Sex & Location & $\begin{array}{l}\text { Primary } \\
\text { complaint }\end{array}$ & $\begin{array}{l}\text { History of } \\
\text { trauma or } \\
\text { repetitive } \\
\text { activity }\end{array}$ & (Refs.) \\
\hline \multirow[t]{2}{*}{ Gravanis and Gaffney, 1983} & 1 & 54 & Male & Right pectoralis minor tendon & NA & NA & (1) \\
\hline & 2 & 28 & Female & Left ring finger, PIP joint & Swelling & NA & (1) \\
\hline \multirow[t]{6}{*}{ Shon and Flope, 2010} & 3 & 16 & Female & Right foot peritendinous tissue & Painful mass & Yes & (2) \\
\hline & 4 & 19 & Female & Right foot peritendinous tissue & Point tenderness & Yes & (2) \\
\hline & 5 & 40 & Female & Right thumb & Painful mass & Yes & (2) \\
\hline & 6 & 63 & Female & Right flexor carpal tendon & Persistent pain & Yes & $(2)$ \\
\hline & 7 & 67 & Female & Right ring finger & Painful mass & Yes & (2) \\
\hline & 8 & 83 & Female & Right middle finger & Painful mass & Yes & (2) \\
\hline Robb et al, 2012 & 9 & 52 & Female & Left knee & Persistent pain & No & (3) \\
\hline Kawata et al, 2014 & 10 & 35 & Male & Left middle finger, PIP joint & Painful swelling & No & $(4)$ \\
\hline Fox et al, 2017 & 11 & 14 & Male & Right ring finger & $\begin{array}{l}\text { Pain, intermittent } \\
\text { locking }\end{array}$ & No & $(5)$ \\
\hline \multirow[t]{22}{*}{ Michal et al, 2018} & 12 & 16 & Female & Right foot & NA & Yes & (6) \\
\hline & 13 & 17 & Female & Left great toe & Pain & Yes & (6) \\
\hline & 14 & 18 & Female & Left IV finger & Nerve tingling & Yes & (6) \\
\hline & 15 & 19 & Female & Right foot MTP joint & Pain & NA & (6) \\
\hline & 16 & 25 & Female & Right toe MTP joint & Pain and edema & Yes & (6) \\
\hline & 17 & 33 & Female & Right IV MCP joint & Swelling with pain & No & (6) \\
\hline & 18 & 33 & Female & Right IV finger PIP joint & Pain & No & $(6)$ \\
\hline & 19 & 38 & Female & Left III finger PIP joint & None & Yes & $(6)$ \\
\hline & 20 & 40 & Female & Right IV finger PIP joint & Pain and edema & No & $(6)$ \\
\hline & 21 & 41 & Female & Right II finger & Pain & No & (6) \\
\hline & 22 & 44 & Female & V finger PIP joint & None & No & $(6)$ \\
\hline & 23 & 44 & Female & Right big toe & None & No & $(6)$ \\
\hline & 24 & 44 & Female & Right IV finger & NA & NA & (6) \\
\hline & 25 & 47 & Female & Left finger & NA & NA & (6) \\
\hline & 26 & 49 & Female & Right hand & NA & NA & (6) \\
\hline & 27 & 49 & Female & Left big toe & Pain and edema & Yes & (6) \\
\hline & 28 & 49 & Female & Right III finger & Pain & No & (6) \\
\hline & 29 & 50 & Female & Left thumb & Pain & NA & (6) \\
\hline & 30 & 52 & Female & Left knee & Pain & No & $(6)$ \\
\hline & 31 & 59 & Male & Left IV finger & NA & NA & $(6)$ \\
\hline & 32 & 63 & Female & Right II finger & NA & NA & (6) \\
\hline & 33 & 75 & Female & Right elbow & Pain & No & $(6)$ \\
\hline Present study & & 66 & Female & Right wrist & Pain & No & - \\
\hline
\end{tabular}

MCP, Metacarpophalangeal; MTP, Metatarsophalangeal; NA, not available; PIP, Proximal interphalangeal.

\section{Availability of data and materials}

All data generated or analyzed during this study are included in this published article.

\section{Authors' contributions}

$\mathrm{CM}$ and $\mathrm{MI}$ were responsible for the conception and design of the study. CM, MI, YH, TT and KT were involved in the acquisition and analysis of the data. CM and MI drafted the manuscript. The final version of the manuscript was read and approved by all authors.

\section{Ethics approval and consent to participate}

This study was conducted in accordance with the Declaration of Helsinki, and written consent was obtained from the patient. 


\section{Patient consent for publication}

Written informed consent for publication was obtained from the patient.

\section{Competing interests}

The authors declare that they have no competing interests.

\section{References}

1. Gravanis MB and Gaffney EF: Idiopathic calcifying tenosynovitis. Histopathologic features and possible pathogenesis. Am J Surg Pathol 7: 357-361, 1983.

2. Shon W and Folpe AL: Tenosynovitis with psammomatous calcification: A poorly recognized pseudotumor related to repetitive tendinous injury. Am J Surg Pathol 34: 892-895, 2010.

3. Robb T, Kimberly O, Strutton GM and McAuliffe M: Tenosynovitis with psammomatous calcification of the knee. Pathology 44: 369-370, 2012.
4. Kawata M, Seki K and Miura T: Tenosynovitis with psammomatous calcification arising from the volar plate of the proximal interphalangeal joint of the finger. Pathol Int 64: 539-541, 2014.

5. Fox MP, McKay JE, Craver RD and Pappas ND: Right ring finger volar mass in a 14-year-old boy. Orthopedics 40: e918-e920, 2017.

6. Michal M, Agaimy A, Folpe AL, Zambo I, Kebrle R, Horch RE, Kinkor Z, Svajdler M, Vanecek T, Heidenreich F, et al: Tenosynovitis with psammomatous calcifications: A distinctive trauma-associated subtype of idiopathic calcifying tenosynovitis with a predilection for the distal extremities of middle-aged women-A report of 23 cases. Am J Surg Pathol 43: 261-267, 2019.

7. Vadon-Le Goff S, Hulmes DJ and Moali C: BMP-1/tolloid-like proteinases synchronize matrix assembly with growth factor activation to promote morphogenesis and tissue remodeling. Matrix Biol 44-46: 14-23, 2015.

8. Liu K, Tripp S and Layfield LJ: Heterotopic ossification: Review of histologic findings and tissue distribution in a 10-year experience. Pathol Res Pract 203: 633-640, 2007.

9. Bai Y, Zhou G, Nakamura M, Ozaki T, Mori I, Taniguchi E, Miyauchi A, Ito Y and Kakudo K: Survival impact of psammoma body, stromal calcification, and bone formation in papillary thyroid carcinoma. Mod Pathol 22: 887-894, 2009. 